\title{
Hepatic Encephalopathy in Liver Cirrhosis: Precipitating factor and Outcome
}

\author{
Khadka $D^{1}$, Shrestha $\mathrm{A}^{2}$,Bassi SD ${ }^{3}$, Bhandari $\mathrm{B}^{4}$
}

\begin{abstract}
Introduction: Hepatic encephalopathy, one of the major decompensating events of liver cirrhosis manifest as a wide spectrum of neurological or psychiatric abnormalities ranging from subclinical alterations to coma. The main aim of this study was to determine precipitants of hepatic encephalopathy (HE) and their impact on hospital stay and mortality. Methods: A hospital based cross sectional study carried out in the Department of Medicine, Nepalgunj Medical College, Kohalpur from September 2018 to May 2019.Patients of liver cirrhosis with signs and symptoms of hepatic encephalopathy(HE) were enrolled in the study. Detailed history was taken with patients or patient's visitor regarding precipitating factors. Child Turcotte Pugh (CTP) class was used for assessing liver disease severity and West Haven classification was used for grading of hepatic encephalopathy. Results: Total patients of hepatic encephalopathy studied were 150. Among which, 114 (76\%) were male and 36 (24\%) were female. Mean age was $45 \pm 11$ years. Common precipitating factors for hepatic encephalopathy identified were constipation $25.3 \%$, Upper gastrointestinal bleed (9.3\%), Spontaneous bacterial peritonitis (8\%). No identifiable factor was observed in $6.7 \%$. cases. Significant relationship was noted with CTP class and grading of Hepatic encephalopathy. Hospital stay was also found longer ( $\geq 5$ days) among patients having more than one precipitating factor. Conclusions: Early recognition of precipitants and patient education is very crucial in the management of hepatic encephalopathy. Patients having $\geq 2$ precipitating factor had longer hospital stay and higher grade of hepatic encephalopathy.
\end{abstract}

\section{Keywords: CTP, Hepatic encephalopathy; Liver cirrhosis; Spontaneous bacterial peritonitis}

\section{INTRODUCTION}

Cirrhosis is the end-stage of every chronic liver disease, characterized by the formation of regenerative nodules of liver parenchyma that are separated by and encapsulated in fibrotic septa and associated with major angioarchitectural changes ${ }^{1}$. Hepatic encephalopathy is one of the major decompensating event in liver cirrhosis, median survival after appearance of encephalopathy is $1-2$ years ${ }^{2}$. The prevalence of overt $\mathrm{HE}$ at the time of diagnosis of cirrhosis is $10 \%-14 \%$ in general ${ }^{3}$, $16 \%-21 \%$ in those with decompensated cirrhosis ${ }^{2}$ and $10 \%-50 \%$ in patients with transjugular intrahepatic portosystemic shunt (TIPS) ${ }^{4}$. Hepatic encephalopathy may arise spontaneously but more commonly will develop as a result of some precipitating factor in the course of acute or chronic liver disease ${ }^{5}$.Early detection of precipitating factor may halt the progression of $\mathrm{HE}$ and prevent fatal complication ${ }^{6}$.Therefore the present study was under taken for early detection of precipitating factor, which will be helpful in

\footnotetext{
1. Dr. Dipendra Khadka

2. Dr. Anil Shrestha

3. Dr. S.D. Bassi

4. Dr. Binus Bhandari
}

\author{
Address for correspondence: \\ Dr. Dipendra Khadka \\ Liver Unit, Department of Medicine \\ Nepalgunj Medical College \& Teaching Hospital \\ Kohalpur, Banke, Nepal \\ Email: khadkadipendra39@gmail.com \\ Phone: +977-9804579465
}

initiating proper management and may also decide the final outcome of patient in terms of hospital stay and mortality.

\section{MATERIAL AND METHODS}

The study was a cross sectional study conducted in the Department of Medicine, Nepalgunj Medical College, Kohalpur from September 2018 to May 2019. Ethical approval was taken from Institutional Review Board (IRB), NGMC and written informed consent was taken from each patient. Patients with liver cirrhosis of age between 18 to 70 years, irrespective of sex with feature of hepatic encephalopathy were included in the study. Patients less than 18 years and more than 70 years of age, Patients with feature of non cirrhotic portal hypertension, acute liver failure, hypo and hyperglycemic coma, stroke and chronic kidney disease with uremia and patients who refuse to participate in the study were excluded from the study.

Patients attending Medicine unit on outdoor basis and or admitted in ward were enrolled in the study, who fulfilled the criteria of liver cirrhosis on clinical, biochemical and radiological background ${ }^{7}$. Hepatic encephalopathy was diagnosed on the basis of history and clinical examination and graded according to West Haven Classification ${ }^{8}$. Severity of liver disease was assessed through the Child Turcotte Pugh (CTP) class $^{9}$. Routine blood examination like complete blood count, liver function, serum albumin, prothrombin time, renal function test, ascitic fluid analysis, urine routine examination, 
chest $x$-ray, ultrasonography abdomen done. Detailed history was taken with patient or patient's visitor regarding precipitating factor like constipation, hematemesis, malena, fever, pain abdomen, diarrhea, intake of high prorein diet, intake of any drugs like sedative, diuretics, large volume paracentesis, trauma or surgery. All patients received standard medical treatment during hospital stay with ammonia lowering and gut cleansing agents such as lactulose and L-ornithine and L-aspartate and other supportive measures. Grade III and IV HE was managed in ICU. Patient with upper gastrointestinal bleeding subsequently underwent an upper gastrointestinal endoscopy upon improvement of HE or earlier in cases of continuing bleeding. Patients were assessed daily till hospital stay.

The desired sample size calculated as

$N=z^{2} p q$

$d^{2}$

$z$-Value for $95 \%$ confidence level

p-Prevalence of hepatic encephalopathy

$q-1-p$

d-Allowable error

Based on different studies, prevalence of HE is $10-14 \%$ in general $^{3}$. Taking prevalence $10 \%$ with allowable error 0.05 , minimum sample size was 138 . Here 150 cases have been studied.

Data collected in structured proforma were entered in Microsoft Excel 2007 and statistical analysis was done with SPSS 20 software. Descriptive analysis of patients with hepatic encephalopathy was performed for demographic and laboratory parameters and results presented as mean \pm standard deviation for quantitative variables Relationship of number of precipitating factors was categorized into 2 categories; one precipitating factor, and more than and equal to 2 precipitating factors and compared it with different parameters using chi-square test. All $p$-values were two sided and considered as statistically significant if $<0.05$.

\section{RESULTS}

A total of 150 patients of liver cirrhosis with HE of different grades were studied, among which 114 (76\%) were male and 36 (24\%) were female. Mean age was $45 \pm 11$ years.Out of 150 cases, majority $130(86.7 \%)$ patients were alchohol related followed by 10 (6.7\%) Hepatitis B virus related and cryptogenic $4(2.6 \%)$. NASH, Autoimmune hepatitis and Hepatitis C infection related cirrhosis was noted in equal percentage $1.33 \%$. Main precipitating factor for HE were constipation (25.3\%), Upper gastrointestinal bleed (9.3\%), Spontaneous bacterial peritonitis (8\%). No identifiable factor was observed in $6.7 \%$.Electrolyte imbalance (hypokalaemia in $4 \%$, hyponatremia in $5.3 \%$ ), high protein diet in $4 \%$, use of sedative in $2.7 \%$ along with combination of one or more precipitating factor noted. Other demographic and laboratory parameters were shown in table l.

\begin{tabular}{|l|l|l|l|}
\hline Variables & Minimum & Maximum & Mean \pm Standard Deviation \\
\hline AGE (years) & 21 & 70 & $45.87 \pm 11.39$ \\
HEMOGLOBIN (g/dl) & 5.7 & 12.5 & $9.811 \pm 1.3$ \\
WBC(cell/cumm) & 1250 & 18900 & $7424.67 \pm 4103.4$ \\
PLATELETS (cell/ $/$ l) & 8700 & 292000 & $144542.67 \pm 62993.1$ \\
BILIRUBIN (mg/dl) & 1.2 & 7.1 & $3.596 \pm 1.3$ \\
ALBUMIN (g/l) & 1.9 & 3.8 & $2.925 \pm 0.4$ \\
INR & 1.0 & 1.9 & $1.372 \pm 0.2$ \\
S.NA (mEq/l) & 120 & 142 & $131.64 \pm 4.4$ \\
S.K (mEq/l) & 3.0 & 4.2 & $3.624 \pm 0.3$ \\
CREATININE (mg/dl) & .6 & 2.1 & $1.111 \pm 0.2$ \\
\hline
\end{tabular}

Table I: Demographics and laboratory parameters of all patients with Hepatic Encephalopathy

S.NA-serum sodium;S.K-serum potassium

Significant relationship was observed between CTP classes and grading of HE. Majority of patients with grade $3 \mathrm{HE}$ were in CTP class $C$ as shown in table II.

\begin{tabular}{|c|c|c|c|c|c|c|c|}
\hline & & \multicolumn{4}{|c|}{ GRADING OF HE } & \multirow[b]{2}{*}{ Total } & \multirow[t]{2}{*}{$\mathrm{p}$-value } \\
\hline & & 1 & 2 & 3 & 4 & & \\
\hline \multirow[t]{6}{*}{ CTP CLASS } & A & 22 & 2 & 0 & 0 & 24 & \multirow{8}{*}{$<0.05$} \\
\hline & & & & & & $(16.0 \%)$ & \\
\hline & B & 0 & 18 & 8 & 0 & 26 & \\
\hline & & & & & & $(17.3 \%)$ & \\
\hline & c & 0 & 0 & 76 & 24 & 100 & \\
\hline & & & & & & $(66.7 \%)$ & \\
\hline \multirow{2}{*}{\multicolumn{2}{|c|}{ Total }} & 22 & 20 & 84 & 24 & 150 & \\
\hline & & & & & & $(100.0 \%)$ & \\
\hline
\end{tabular}

Table II: Relationship between CTP class and grading of HE

Majority of patients (96) out of 150 were having one precipitating factor. There was no significant relationship observed between CTP class and number of precipitating factor but significant relation observed for grading of $\mathrm{HE}$ and duration of hospital stay with increase in number of precipitating factors but not with patients survival as shown in table III.

\begin{tabular}{|c|c|c|c|c|}
\hline Variable & $\begin{array}{c}<=1 \\
\text { precipitating } \\
\text { factor }\end{array}$ & $\begin{array}{c}>=2 \\
\text { precipitating } \\
\text { factor }\end{array}$ & Total & p-value \\
\hline $\begin{array}{c}\text { CTP CLASS } \\
\text { A } \\
\text { B } \\
\text { C }\end{array}$ & $\begin{array}{l}18(18.8 \%) \\
20(20.8 \%) \\
58(60.4 \%)\end{array}$ & $\begin{array}{c}6(11.6 \%) \\
6(11.6 \%) \\
42(77.8 \%)\end{array}$ & $\begin{array}{c}24(16.0 \%) \\
26(17.3 \%) \\
100(66.7 \%)\end{array}$ & 0.095 \\
\hline $\begin{array}{c}\text { Grading of } \mathrm{HE} \\
1 \\
2 \\
3 \\
4\end{array}$ & $\begin{array}{c}18(18.8 \%) \\
14(14.6 \%) \\
60(62.5 \%) \\
4(4.2 \%)\end{array}$ & $\begin{array}{c}4(7.4 \%) \\
6(11.1 \%) \\
24(44.4 \%) \\
20(37.0 \%)\end{array}$ & $\begin{array}{l}22(14.7 \%) \\
20(13.3 \%) \\
84(56.0 \%) \\
24(16.0 \%)\end{array}$ & $<0.05$ \\
\hline $\begin{array}{c}\text { Duration of } \\
\text { hospital stay } \\
<5 \text { days } \\
\geq 5 \text { days }\end{array}$ & $\begin{array}{l}40(41.7 \%) \\
56(58.3 \%)\end{array}$ & $\begin{array}{c}4(7.4 \%) \\
50(92.6 \%)\end{array}$ & $\begin{array}{c}44(29.3 \%) \\
106(70.7 \%)\end{array}$ & $<0.05$ \\
\hline $\begin{array}{l}\text { Outcome } \\
\text { Alive } \\
\text { Dead }\end{array}$ & $\begin{array}{c}94(97.9 \%) \\
2(2.1 \%)\end{array}$ & $\begin{array}{c}50(92.6 \%) \\
4(7.4 \%)\end{array}$ & $\begin{array}{c}144(96.0 \%) \\
6(4.0 \%)\end{array}$ & 0.19 \\
\hline Total & 96 & 54 & 150 & \\
\hline
\end{tabular}

Table III: Relationship of numbers of precipitating factors with different parameters 


\section{DISCUSSION}

Hepatic encephalopathy (HE) is a complex, potentially reversible neuro-psychiatric condition may arise spontaneously but more commonly will develop as a result of some precipitating factors. Modern research has proved time and again that identifying and removing precipitating factors is still the key step in the overall management ${ }^{10}$. In our study, significant relationship was noted between grading of $\mathrm{HE}$ with CTP class which represents disease severity. Higher grade of $\mathrm{HE}$ with CTP class $\mathrm{C}$ was also reported by Nayak, et al ${ }^{11}$. Among different precipitating factors of $\mathrm{HE}$, constipation, upper gastrointestinal bleeding and spontaneous bacterial peritonitis, high protein intake were found in majority. Similar observations were reported by other studies too ${ }^{12,13}$. Constipation and gastrointestinal bleed increases ammonia production and absorption thus precipitate HE. The present study demonstrates that a longer hospital stay in patients with $\geq 2$ precipitating factors as compared to Strauss et al $^{14}$. Longer hospital stay is associated with increased risk of hospital acquired infections which further exacerbate $\mathrm{HE}$ episodes. Thus, it is very important that early recognition of precipitating factor play a key role in final outcome of patients of HE.

\section{CONCLUSION}

Hepatic encephalopathy is one of the major decompensating events of liver cirrhosis usually associated with precipitating factors. Constipation, GI bleeding, Infection were identified as major precipitating factor. Patient education is very important regarding knowledge of disease condition and its precipitating factors because $\mathrm{HE}$ is reversible condition if precipitating factors are recognized early and treated properly.

\section{ACKNOWLEDEMENT}

I would like to thank Mr. Gaurav Jung Shah for kind support during statistical analysis.

\section{REFERENCES}

1. Rappaport AM, McPhee PJ, Fisher MM, Phillips MJ: The scarring of the liver acini (cirrhosis). Tridimensional and microcirculatory considerations. Virchows Arch A Pathol Anat Histopathol 1983;402:107-37.

2. D'Amico G, Morabito A, Pagliaro L, Marubini E. Survival and prognostic indicators in compensated and decompensated cirrhosis. Dig Dis Sci. 1986;31:468-75.

3. Romero-Gomez M, Boza F, Garcia-Valdecasas MS, et al. Subclinical hepatic encephalopathy predicts the development of overt hepatic encephalopathy. Am J Gastroenterol 2001; 96:2718-23.

4. Papatheodoridis GV, Goulis J, Leandro G, Patch D, Burroughs AK. Transjugular intrahepatic portosystemic shunt compared with endoscopic treatment for prevention of variceal rebleeding: a meta-analysis.
Hepatology 1999;30:612-22.

5. Worobetz LJ. Hepatic encephalopathy. In: Thomson AR, Shaffer EA, (Eds.) First Principles of Gastroenterology. 3rd edition Toronto: University of Toronto press; 2000. p. 537-39.

6. Mullen KD, Dasarathy S. Hepatic encephalopathy. In: Schiff ER, Sorrell MF, Maddrey WC, (Eds). Schiff's Diseases of the Liver. 8th ed. Philadelphia: Lippincott Raven Publishers; 1999. p. 545-81.

7. Syed VA, Ansari JA, Karki P, Regmi M, Khanal B. Spontaneous bacterial peritonitis (SBP) in cirrhotic ascites: a prospective study in a tertiary care hospital, Nepal. Kathmandu Univ Med J (KUMJ). 2007;5(17) :4859.

8. Ferenci P, Lockwood A, Mullen K, Tarter R, Weissenborn K, Blei A. Hepatic encephalopathy--definition, nomenclature, diagnosis, and quantification: final report of the working party at the 11th World Congresses of Gastroenterology, Vienna, 1998. Hepatology 2002; 35:716-21.

9. Hong SH, Kim JE, Cho ML, Heo YJ, Choi JH, Choi JH et al. Comparison of the Child-Turcotte-Pugh classification and the model for end-stage liver disease score as predictors of the severity of the systemic inflammatory response in patients undergoing living-donor liver transplantation. J Korean Med Sci. 2011 Oct 1;26(10):1333-38

10. Cordoba J.Blei AT. Treatment of hepatic encephalopathy. American Journal of.Gastroenterology. 1997;92:142939.

11. Nayak M, Anubhaw N, Nayak R. Incidence of Hepatic Encephalopathy in Cirrhosis of Liver.International journal of Contemporary Medical research.2016; 3(12): 7783nter

12. Alam I, Razaullah, Haider I, Hamayun M, Taqweem A, Nisar M. Spectrum of precipitating factors of hepatic encephalopathy in liver cirrhosis. Pak J Med Res 2005; 44:96-100.

13. Blei AT, Córdoba J. Practice Parameters Committee of the American College of Gastroenterology. Hepatic encephalopathy. Am J Gastroenterol 2001; 96:1968-76. Nation

14. Strauss E, da Costa MF. The importance of bacterial infection as precipitating factor of chronic hepatic encephalopathy. Hepatogastroenterology 1998; 45:9004. $n$ of 